\title{
A PROPOSAL FOR FLICKER EVALUATION
}

\author{
Arnaldo José Pereira Rosentino Junior, José Rubens Macedo Junior, Antônio Carlos Delaiba \\ Faculty of Electrical Engineering, Federal University of Uberlândia - UFU \\ Uberlândia - MG \\ e-mail: arnaldoufu@gmail.com
}

\begin{abstract}
The measured flicker levels by using the IEC standard 61000-4-15 often far exceed the established compatibility levels, even without the existence of consumer complaints. The poor measurement/complaint correlation due to the use of IEC flickermeter can be explained by two significant hypotheses. Firstly, modern lightning may be significantly less sensitive to voltage fluctuations than standard incandescent lamps upon which the entire IEC flickermeter concept is based. As a result, the luminous flux density (illuminance) variation from modern lamp bulbs is not well represented by the IEC flickermeter. Furthermore, the IEC standard 610004-15 is not able to detect flicker caused by high interharmonics components. In this connection, the flicker severity index measured by the IEC flickermeter to evaluate the flicker effect in modern lamp bulbs is controversial. Thus, would be the flicker planning levels and flicker requirements adequate to this scenario? This work presents a method to evaluate the flicker effect by taking into account the direct response of the illuminance variation. The test results have indicated a better correlation between measured flicker level and user complaint for all lamps tested in this study.
\end{abstract}

Keywords - Flicker, IEC flickermeter, Illuminance, Interharmonic, Voltage fluctuation.

\section{INTRODUCTION}

According to the International Electrotechnical Vocabulary (IEV) [1] of the International Electrotechnical Committee (IEC), flicker is defined as "Impression of unsteadiness of visual sensation induced by a light stimulus whose luminance or spectral distribution fluctuates with time".

The flicker assessment can be divided in three different tasks: disturbance source modelling, measurement and mitigation. The main flicker source are the time-varying loads, including both regularly and irregularly fluctuating loads [2]. The most commonly used devices to improve the voltage fluctuations in power system are the static VAR or reactive compensators (being var the volt ampere reactive) and the distribution static synchronous compensator (DSTATCOM) [3]. Other alternatives for mitigating the flicker effect are related to series compensation [4] and optimized half-cycle power control [5]. The accepted worldwide protocol for flicker measurement is the IEC

${ }^{1}$ Manuscript received 21/03/2014; revised 02/06/2014; accepted for publication August 08/08/2014, by recommendation of the Regular Section Editor Cassiano Rech. standard 61000-4-15 [6]. However, this work will focus on the meter issue since in some situations the IEC protocol does not present a good correlation between the magnitude of the measured index and the flicker effect itself. According to IEC standard 61000-4-15, the voltage fluctuation disturbance must be measured and quantified using a measurement instrument called flickermeter. The IEC flickermeter quantifies the physiological malaise suffered by the human eye when subjected to a luminous fluctuation of a reference incandescent lamp (IL). However, due to energy-saving measures related to lighting, the incandescent lamps are being banned and replaced by modern energy efficient lamps (for example, compact fluorescent lamp (CFL) and lightemitting diode (LED) lamp). This new scenario has revealed some flickermeter limitations. There are situations that light flicker effect is noted in fluorescent lamps, while for incandescent lamps is not observed any problem [7]. Then, the flickermeter would be probably omitting an existing disturbance at the electrical system. Moreover, it is worthwhile to highlight that voltage fluctuation is not only correlated to load abrupt changes, but it is also associated with the presence of interharmonic components in the power line [8]-[11]. As consequence, this scenario can represent a fragile structure to measure the relationship between the impact of voltage fluctuations on electronic equipment supplied by switched sources. In accordance with [12], it is shown that the filter capacitor will acumulate and dissipate higher amount of charge when the rectifier is subjected to ac source voltage fluctuations. In fact, the rms value of the capacitor current will increase as the voltage modulation varies in frequency and magnitude. This is the reason that explains the effect of the supply with a voltage fluctuation component containing inter-harmonics upon the switched source stresses and the correponding reduction on the equipment life expectance.

Many works have proposed new methods or even IEC flickermeter improvements aiming to obtain a better correlation between an index that quantifies the light flicker effect and the user complaint. Some enhancements of the standard flickermeter have been suggested [13]-[16], but the most promising proposals show that correct and reliable measurements of the annoyance produced by flicker can be performed only by direct measurement and process of the light emitted by the actual lamp. In [17], the flickermeter is improved by using different weighting filters, which can represent the flicker responses for different lamp technologies. Even though different lamps types are represented, the model was not evaluated with the presence of interharmonics components. A dynamic analytical model of the eye-brain system has been presented and discussed in [18] and [19]. However, the authors have revealed that the 
model is a simplified representation of a highly complex phenomenon and they are still testing the validity of the proposed model. The eye-brain response to flicker effect by studying the relationship between light and human optic nerve blood flow has been proposed in [20]. There is also a study focused on the measurement of the pupil diameter under flicker conditions [21]. However, the experimental results of aforementioned references are preliminary and more research is necessary. Some works analyse the luminous flux density behavior due to voltage fluctuation effect [22], [23]. In [22] the authors used the illuminance response just to make evident the IEC flickermeter deficiency, that is, they do not propose any method to improve the flicker evaluation. On the other hand, in [23] is proposed a modified flickermeter using the direct measurement of the light emitted by the lamp. But this work analyses just the flicker effect. It is worthwhile to highlight that the flicker is just one effect of the possible impacts caused by voltage fluctuation.

It is clear that the flickermeter presents deficiencies and the interest of the scientific community has been focused on the development of improved measurement techniques. In this connection, this paper proposes a new technique focused on the luminous flux density variation and on the original flickermeter Pst curve to qualify and quantify the light flicker effect. Then, a new sensibility curve is suggested. From such curve will be able to extend the impact of voltage fluctuation to other effects, without using the direct measurement of the light emitted, but just the voltage signal. The paper is organized as follows: Section II highlights the limitations of IEC standard 61000-4-15 through a theoretical and laboratorial analysis. The illuminance variation characteristic in incandescent lamp, LED lamp and compact fluorescent lamp as well is shown in Section III. Section IV introduces the new technique and reports the main results of the study. Finally, conclusions are summarized in Section V.

\section{DEFICIENCIES OF THE IEC FLICKERMETER}

IEC flickermeter has been widely accepted as an international standard for flicker severity measurement. However, the IEC standard 61000-4-15 is unable to measure flickers caused by interharmonics whose frequencies are higher than $102 \mathrm{~Hz}(60 \mathrm{~Hz}$ systems $)$ or $85 \mathrm{~Hz}(50 \mathrm{~Hz}$ systems) [8]. Such interharmonics are not uncommon. Current or voltage source inverter based variable frequency drives (VFDs), phase angle and cycle-by-cycle power control, HVDC links, and other static-frequency converters can become major sources of such interharmonics in power systems [2], [5].

Aiming to know more about such deficiency, it is interesting to describe some characteristics of IEC standard 61000-4-15. The IEC flickermeter is essentially a signal processing tool, which has the voltage as input signal and the instantaneous flicker sensation as output signal. Figure 1 shows the block diagram of the IEC flickermeter.

If the fluctuation magnitude is sufficiently large and the fluctuation frequency is in a range perceptible by human eyes $(0.5$ to $30 \mathrm{~Hz})$, a light flicker will occur. It is documented that the voltage fluctuation magnitude as small as $0.32 \%$ of the fundamental magnitude at critical flicker frequency (8.8 $\mathrm{Hz}$ ) can cause light flicker [8].

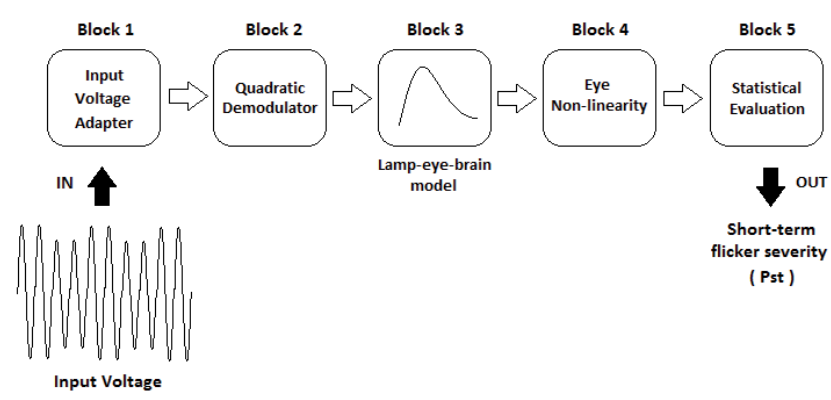

Fig. 1. Block diagram of the IEC flickermeter.

The functionality of each of the five blocks of the IEC flickermeter is described as follows [6], [24]:

- Block 1: scales the input voltage level to an internal reference value;

- Block 2: recovers the voltage fluctuation by squaring the scaled input voltage;

- Block 3: it is composed specially of a weighting filter, which simulates the frequency response of the human visual system to sinusoidal voltage fluctuations of an incandescent lamp. The point of maximum sensitivity to flicker is approximately $8.8 \mathrm{~Hz}$;

- Block 4: simulates the nonlinear eye-brain perception and provides a sliding mean averaging of the signal to simulate the storage effect in the brain;

- Block 5: performs the statistical classification of the instantaneous flicker sensation, i.e., the output of Block 4. This computation over 10 minutes is defined as the short-term flicker severity, called Pst. The long-term flicker severity, called Plt, shall be derivate from the short-term severity values, $P$ st, over an appropriate period related to the duty cycle of the load or a period over which an observer may react to flicker. It is recommended 2 hours period, i.e., 12 Pst values [5], [25]. The recommended practice for measurement and limits of voltage fluctuations can be found in [26].

\section{A. Theoretical Analysis}

When a voltage waveform contains interharmonics, the rms and peak magnitudes of the waveform will fluctuate in a corresponding way. These interharmonic components are classically produced by VFDs, arc furnaces and fluctuating loads, amongst others. By taking into account the current (CSI) or voltage (VSI) source inverters, the produced interharmonic frequencies are largely dependent on the dc side ripple. For example, for a 6-pulse rectifier, the characteristic frequencies are $60 \mathrm{~Hz}, 300 \mathrm{~Hz}, 420 \mathrm{~Hz}, 660$ $\mathrm{Hz}$, etc. If the dc side has a ripple of $177 \mathrm{~Hz}$, the ac side current will be modulated as $60 \pm 177 \mathrm{~Hz}, 300 \pm 177 \mathrm{~Hz}, 420$ $\pm 177 \mathrm{~Hz}, 660 \pm 177 \mathrm{~Hz}$, etc. Concerning the arc furnaces, significant interharmonics are found around the supply voltage fundamental frequency. The dc arc furnace can be characterized by a significant presence of interharmonics around the harmonics of the ac/dc converters. Due to the chaotic behavior of the arc, the interharmonics generated by these devices are characterized by a random change of the 
frequencies. As for the regularly fluctuating loads (laser printers, welder machines, devices with integral cycle control), once again a large harmonic and interharmonc spectrum may be found [27]. Finally, it must be stressed that the interharmonic frequencies produced by such equipment are largely produced bellow $100 \mathrm{~Hz}$.

In this regard, aiming to analyze the interharmonic effect, a careful analysis of IEC flickermeter performance using the LabView platform is presented in this section. The simulations are based on the following voltage signal [8], [9]:

$$
v=V_{1}\left[\sin \left(2 \pi f_{1} t\right)+A_{I H} \sin \left(2 \pi\left(f_{1}+\Delta f\right) t+\theta_{I H}\right)\right]
$$

where:

$$
\begin{array}{ll}
V_{1} & \text { - fundamental voltage peak magnitude; } \\
f_{1} & \text { - fundamental frequency; } \\
A_{I H} & \text { - interharmonic relative magnitude; } \\
f_{1}+\Delta f=f_{I H} & \text { - interharmonic frequency; } \\
\theta_{I H} & \text { - interharmonic phase angle. }
\end{array}
$$

Figure 2 shows the $P s t$ values after varying $\Delta f$ from 45 to $140 \mathrm{~Hz}$, i.e., taking into account an interharmonic range from 105 to $200 \mathrm{~Hz}$, with relative magnitude of $0.05-1.0 \mathrm{pu}$. It worthwhile to highlight that superposition of an interharmonic component can cause modulation just in the range from 0 to $30 \mathrm{~Hz}$ [22].

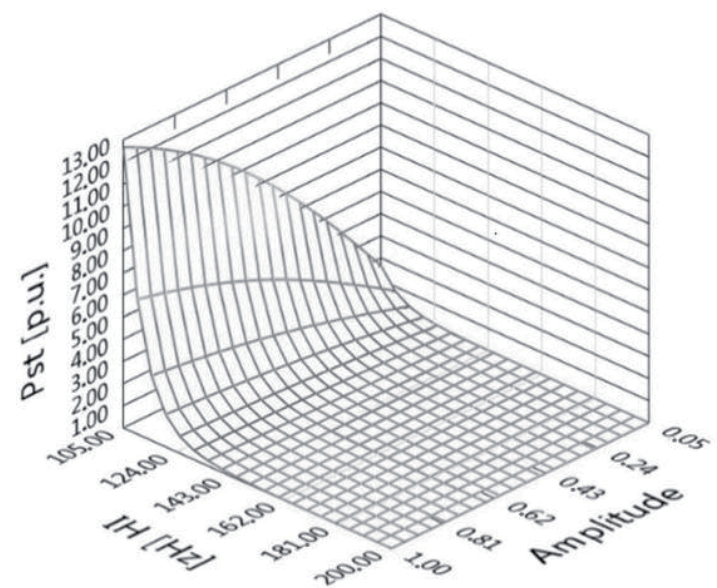

Fig. 2. Pst characteristic against interharmonic relative magnitude and frequency.

It can be seen that when the interharmonic frequency is very high, even if the interharmonic magnitude is equal to the fundamental frequency magnitude, the Pst is very small, indicating no flicker. It is concluded that the IEC flickermeter cannot assess flicker caused by high interharmonics frequencies. A careful analysis of the flickermeter algorithm reveals that the problem is caused by the band-pass filter of Block 3 or by the squaring function of Block 2 of the IEC flickermeter. The filter eliminates the DC and high frequency components since it is judged that human brains are not sensitive to those frequencies [8], [9].

\section{B. Laboratorial Analysis}

Figure 3 summarizes a schematic diagram of flicker experimental setup developed to investigate the poor correlation between measured flicker level and user complaint under interharmonics in three different types of lamps, as follows:

- Incandescent lamp (IL): When the current flows through the resistance of the filament, energy is released in the form of heat and light [28]. Due to the simple model of such lamp, different manufactures will have similar flicker response. Moreover, such lamp is more sensitive to rms voltage fluctuation [9];

- Compact fluorescent lamp (CFL): The compact fluorescent lamp comprises five blocks: AC filter, rectifier, DC filter, inverter and the light bulb [23]. In this work, a popular model with electronic ballast to represent the great part of the compact fluorescent lamp was used. Such lamp present similar flicker response to other ones and they are more sensitive to peak voltage fluctuation [9]. It is worthwhile to highlight that light output from fluorescent lamps is mainly determined by power applied to them, because the arc discharging power provided by an ac ballasting circuit tends to cause the cyclic variation and thus lead to fluctuation in light output [29];

- LED lamp: This device is also equipped with a voltage converters. A typical low-wattage LED ballast consists of an electromagnetic interference (EMI) filter, a diode bridge full wave rectifier for converting $\mathrm{AC}$ to $\mathrm{DC}$, a smoothing capacitor which provides pure DC link voltage to the converter, a PWM controlled constant current source converter for DC to DC conversion, and an array of LEDs. In this work, it was used a LED lamp with similar response to CFL. This results that LED lamps are more sensitive to peak voltage fluctuation than rms voltage fluctuation. However, due to the effects of the junction temperature on the LED luminous efficacy, it is worthwhile to highlight that can be found LED lamps, which are more or less sensitive to voltage fluctuation since can exist different thermal designs [30], [31].

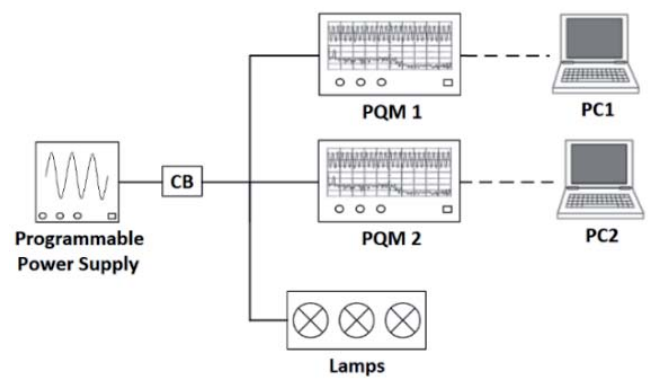

Fig. 3. Schematic diagram of flicker experimental setup.

The system as shown in Figure 3 can be separated into the following parts:

- Programmable Power Supply: It generates the voltage fluctuation disturbance;

- Circuit Breaker (CB): Overcurrent protection device of the electrical installation;

- Lamps:

- IL: OSRAM, $60 \mathrm{~W}, 127 \mathrm{~V}-60 \mathrm{~Hz}$

- CFL: FLC, $20 \mathrm{~W}, 127 \mathrm{~V}-60 \mathrm{~Hz}, 3 \mathrm{U}$ type;

- LED: ECOLUME PAR20, 3 W, 127 V.

- Power Quality Meter 1 (PQM 1): Reference device meter used for Pst evaluation; 
- PC 1: Data analysis of PQM 1;

- Power Quality Meter 2 (PQM 2): It allows observation of current and voltage waveform through PC 2;

- $\quad$ PC 2: Data analysis of PQM 2.

The programmable power source used in this work generates pairs of inter-harmonic components. Thus, a frequency setting equal to $105 \mathrm{~Hz}$ will produce a pair of interharmonics at $45 \mathrm{~Hz}$ and $165 \mathrm{~Hz}$, i.e., $|60 \mathrm{~Hz} \pm 105 \mathrm{~Hz}|$. Then, such pair of interharmonics will cause a voltage modulation of $15 \mathrm{~Hz}$, which can be explained as follows [11]:

$$
\begin{aligned}
& f_{\text {fluctuation }}=\left|f_{I H 1}-h_{I H 1} \cdot f_{1}\right|=\left|f_{I H 2}-h_{I H 2} \cdot f_{1}\right| \\
& f_{\text {fluctuation }}=|45-1 \cdot 60|=|165-3 \cdot 60|=15 \mathrm{~Hz}
\end{aligned}
$$

where:

$f_{I H 1} \quad$ - interharmonic frequency 1 ;

$f_{I H 2} \quad$ - interharmonic frequency 2 ;

$h_{I H 1} \quad$ - harmonic order closest to $f_{I H 1}$;

$h_{I H 2}$ - harmonic order closest to $f_{I H 2}$.

In this regard, the programmable power supply can be used to generate high interharmonics frequencies. Therefore, aiming to detect the flicker light effect and analyze the IEC flickermeter performance, voltage fluctuations with different magnitudes and frequencies were applied to three lamps types, as follows: $60 \mathrm{~W}-127 \mathrm{~V}$ incandescent lamp, $15 \mathrm{~W}-127 \mathrm{~V}$ compact fluorescent lamp, and 3W-127V LED lamp. Table I shows the frequency settings at programmable power supply to investigate each lamp. The three studied cases were chosen in such a way to analyze different frequency ranges.

TABLE I

Case Studies

\begin{tabular}{ccccc}
\hline Case & $\begin{array}{c}\text { Frequency } \\
(f) \\
(\mathbf{H z})\end{array}$ & $\begin{array}{c}\text { Fluctuation } \\
\text { Magnitude }(\boldsymbol{m}) \\
(\boldsymbol{\%})\end{array}$ & $\begin{array}{c}f_{I H 1} \\
(\mathbf{H z})\end{array}$ & $\begin{array}{c}f_{I H 2} \\
(\mathbf{H z})\end{array}$ \\
\hline 1 & 10 & 1 & 50 & 70 \\
\hline 2 & 166.5 & 8 & 106.5 & 226.5 \\
\hline 3 & 200 & 10 & 140 & 260 \\
\hline
\end{tabular}

1) Case 1 - From Table II, it can be seen that the Pst for the three lamps types is in agreement with the flicker perception, that is, the IEC flickermeter did not present any problem.

TABLE II

Case Study 1 Results

\begin{tabular}{cccc}
\hline \multirow{2}{*}{ Parameter } & \multicolumn{3}{c}{ Lamp Type } \\
\cline { 2 - 4 } & IL & CFL & LED \\
\hline Pst $[\mathrm{pu}]($ IEC Flickermeter) & 2.49 & 2.49 & 2.49 \\
\hline Flicker perception & Yes & Yes & Yes \\
\hline Fluctuation frequency $[\mathrm{Hz}]$ & 10 & 10 & 10 \\
\hline
\end{tabular}

Figure 4 illustrates the pair of interharmonics for this case study. It can be noted that both frequencies match with those presented in Table I.

Even though the relative magnitude for this study case is just $1.0 \%$, it was observed flicker effect in all lamps. It is explained by the voltage modulation being close to the point of maximum sensitivity to flicker $(8.8 \mathrm{~Hz})$. Figures 5 and 6 can also highlight this fact. It can be seen a peak voltage modulation (see Figure 5), and a rms voltage modulation as well (see Figure 6). It is worthwhile to highlight that incandescent lamps are sensitive to rms voltage fluctuation, while the compact fluorescent lamps are sensitive to peak voltage fluctuation. Moreover, from the experimental results, it was verified that the LED lamp exhibits flicker response similar to that of compact fluorescent lamp.

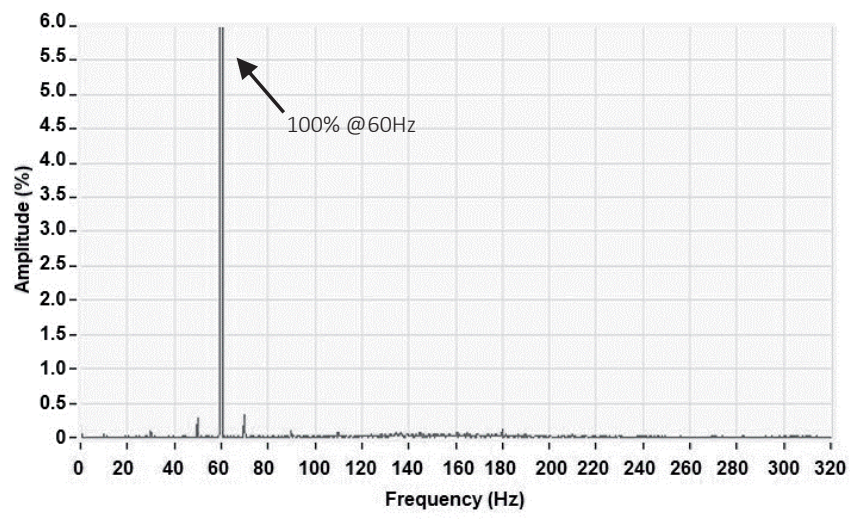

Fig. 4. Voltage frequency spectrum for tests in CFL, IL and LED lamp. Case study 1: $f=10 \mathrm{~Hz}, m=1 \%$.

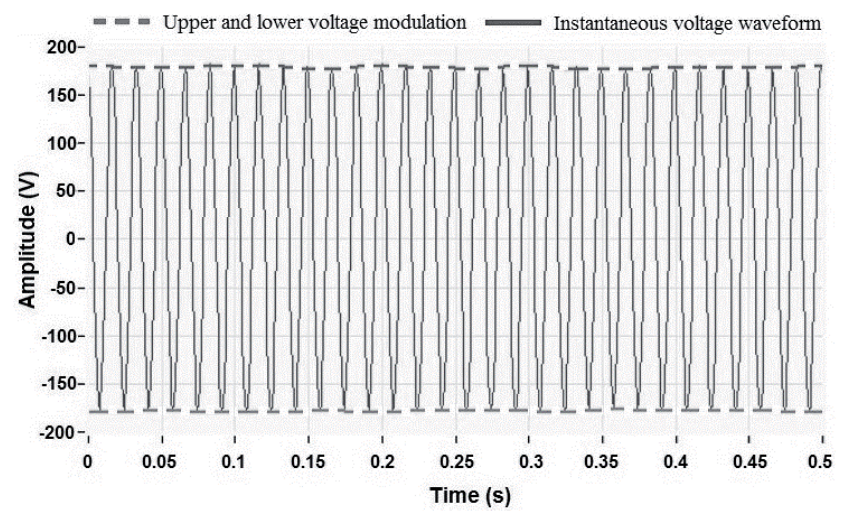

Fig. 5. Voltage waveform for tests in CFL, IL and LED lamp. Case study $1: f=10 \mathrm{~Hz}, m=1 \%$.

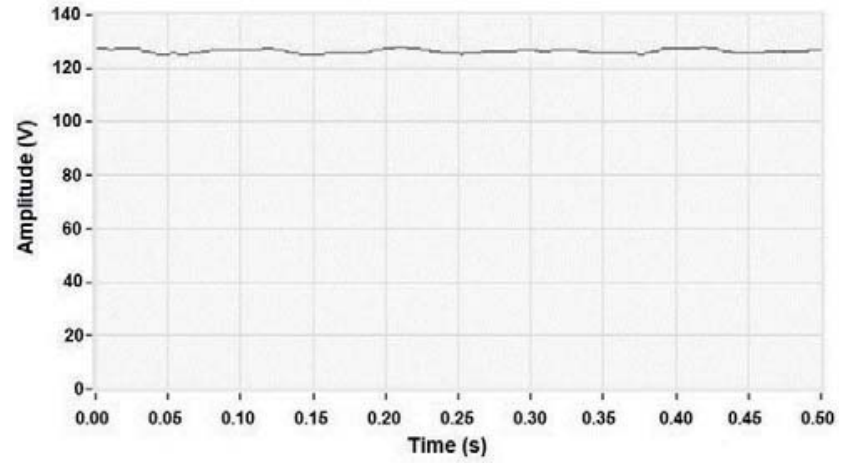

Fig. 6. RMS voltage for tests in CFL, IL and LED lamp. Case study 1: $f=10 \mathrm{~Hz}, m=1 \%$.

2) Case 2 - Table III presents the results for case study 2 and highlights the IEC flickermeter deficiency. It can be observed that exists a discrepancy between the Pst value and the user complaint for the CFL and LED lamp. As described before, this deficiency can be explained by the high 
interharmonics components. In this case study, the voltage waveform contains a pair of interharmonics at $106.5 \mathrm{~Hz}$ and $226.5 \mathrm{~Hz}$. Figure 7 illustrates the frequency spectrum.

The results can also be justified by analyzing the peak and rms voltage fluctuation. The peak voltage fluctuation of 13.5 $[\mathrm{Hz}]$ is clearly noted by seeing Figure 8 . As a result, there is flicker effect in the CFL and LED lamp. On the other hand, there is no much rms voltage fluctuation (see Figure 9). Therefore, there is no flicker effect in the incandescent lamp.

TABLE III

Case Study 2 Results

\begin{tabular}{cccc}
\hline \multirow{2}{*}{ Parameter } & \multicolumn{3}{c}{ Lamp Type } \\
\cline { 2 - 4 } & IL & CFL & LED \\
\hline Pst $[\mathrm{pu}]($ IEC Flickermeter $)$ & 0.53 & 0.74 & 0.79 \\
\hline Flicker perception & No & Yes & Yes \\
\hline Fluctuation frequency $[\mathrm{Hz}]$ & 13.58 & 13.58 & 13.58 \\
\hline
\end{tabular}

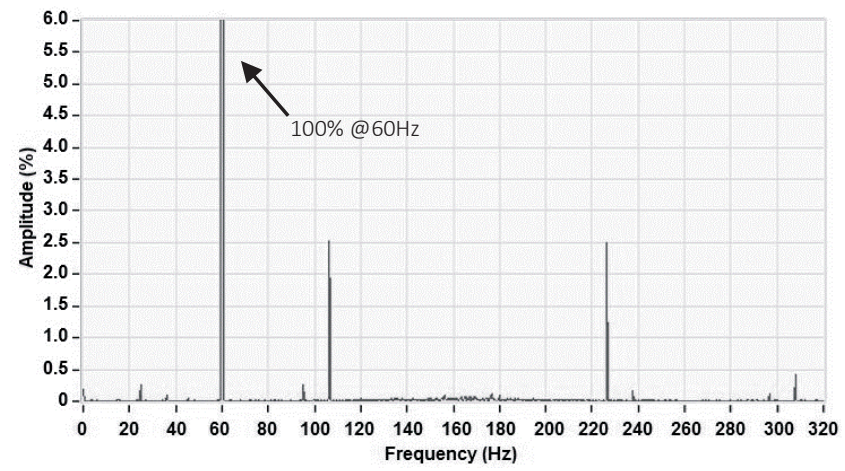

Fig. 7. Voltage frequency spectrum for tests in CFL, IL and LED lamp. Case study 2: $f=166.5 \mathrm{~Hz}, m=8 \%$.

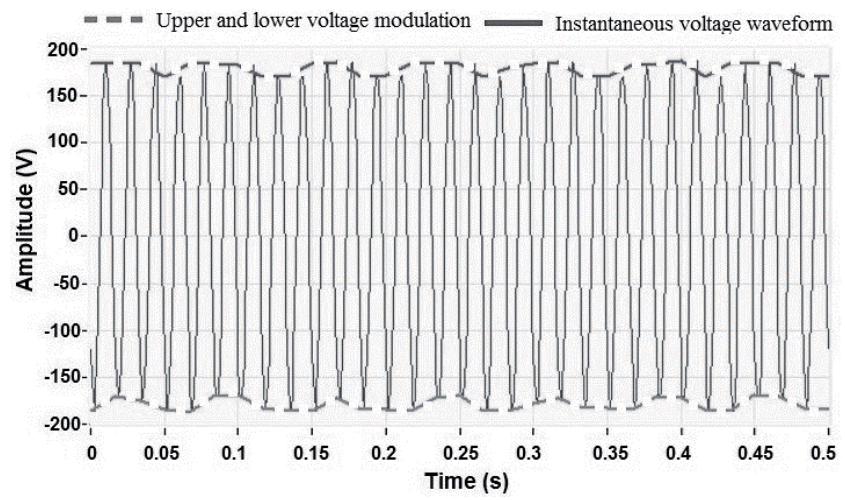

Fig. 8. Voltage waveform for tests in CFL, IL and LED lamp. Case study 2 : $f=166.5 \mathrm{~Hz}, m=8 \%$.

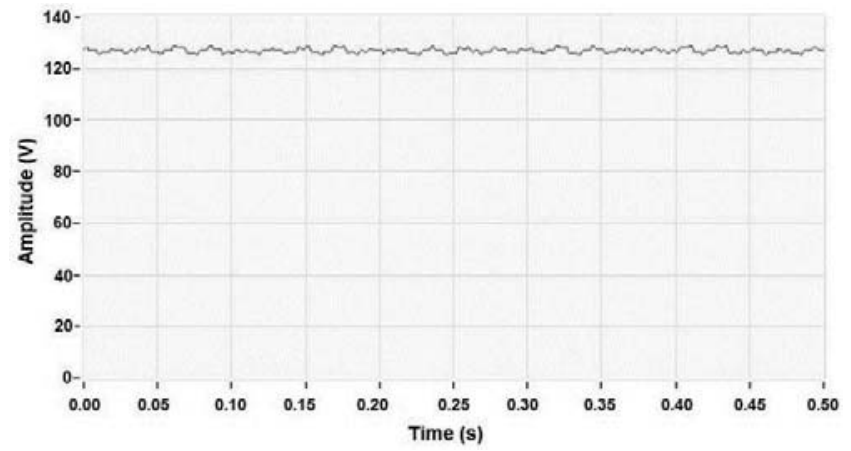

Fig. 9. RMS voltage for tests in CFL, IL and LED lamp. Case study 2: $f=166.5 \mathrm{~Hz}, m=8 \%$.
3) Case 3 - Finally, as shown in Table IV, for this case study the measured Pst by the IEC flickermeter is in agreement with the human observation of flicker taking into account all lamps.

\section{TABLE IV}

Case Study 3 Results

\begin{tabular}{cccc}
\hline \multirow{2}{*}{ Parameter } & \multicolumn{3}{c}{ Lamp Type } \\
\cline { 2 - 4 } & IL & CFL & LED \\
\hline$P s t[\mathrm{pu}]($ IEC Flickermeter) & 0.44 & 0.46 & 0.47 \\
\hline Flicker perception & No & No & No \\
\hline Fluctuation frequency $[\mathrm{Hz}]$ & 19.7 & 19.8 & 19.8 \\
\hline
\end{tabular}

Figure 10 presents the voltage frequency spectrum for such case study. Even though in such case study was applied the highest relative magnitude $(10 \%)$, this value is not enough to produce a flicker effect at the frequency modulation equal to $20 \mathrm{~Hz}$ (far from the point of maximum sensitivity of flicker), which is result of $140 \mathrm{~Hz}$ and $200 \mathrm{~Hz}$ interharmonics components. Figures 11 and 12 illustrate, respectively, the peak voltage fluctuation and the rms voltage fluctuation.

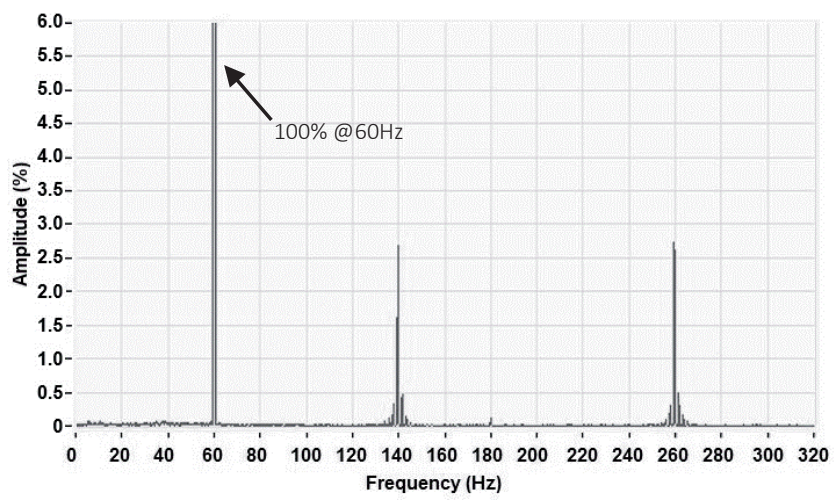

Fig. 10. Voltage frequency spectrum for tests in CFL, IL and LED lamp. Case study 3: $f=200 \mathrm{~Hz}, m=10 \%$.

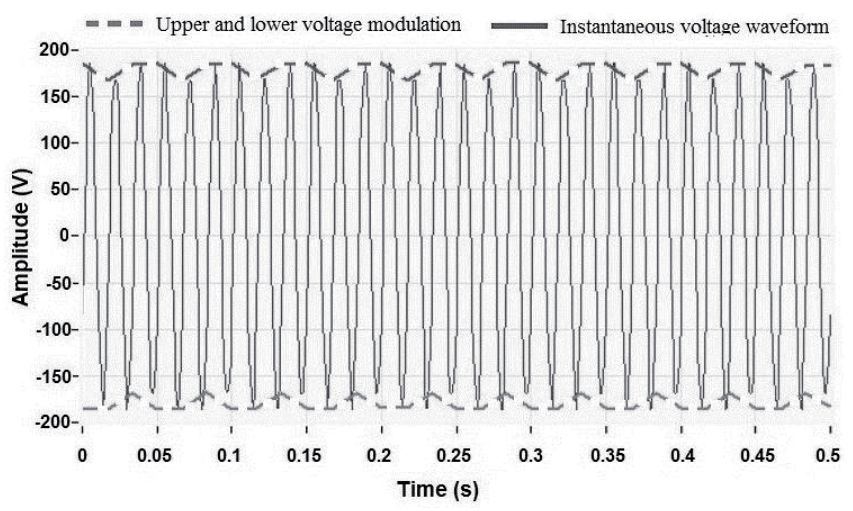

Fig. 11. Voltage waveform for tests in CFL, IL and LED lamp. Case study 3: $f=200 \mathrm{~Hz}, m=10 \%$.

\section{ANALYSIS OF LUMINOUS FLUX DENSITY VARIATION}

Due to the clear IEC flickermeter deficiency discussed so far, the scientific community has been focused on the development of improved measurement techniques to evaluate the flicker effect. In this study, it was analyzed the response of illuminance under voltage fluctuation 
/interharmonics and it is proposed a first step of a new method to quantify and qualify the flicker effect, called a "Flicker Lux Meter".

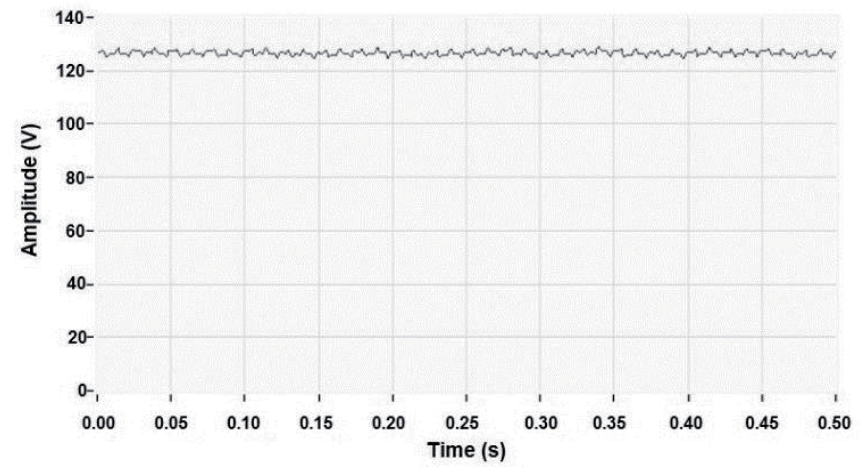

Fig. 12. RMS voltage for tests in CFL, IL and LED lamp. Case study 3: $f=200 \mathrm{~Hz}, m=10 \%$.

To evidence the response of illuminance under interharmonics, some results related to the case study 2 are presented. This case study was chosen since it has indicated the IEC flickermeter limitation. To perform the experimental setup, as illustrated by Figure 13, two more devices were added to that one shown in Figure 3, as follows:

- Light Sensor: Aiming at measuring the luminous flux density variation. The equipment is manufactured by INSTRUTHERM and it has a sensor to provide the spectral response in a similar way to the human eye response. The equipment herein referred has been housed in a black box with the lamp under test;

- $\quad$ NI Device Data Acquisition (DAQ): NI USB-6008 (14bit, $12 \mathrm{kS} / \mathrm{s}$ ). It receives the analogic signal from the light sensor and sends the data to PC 2.

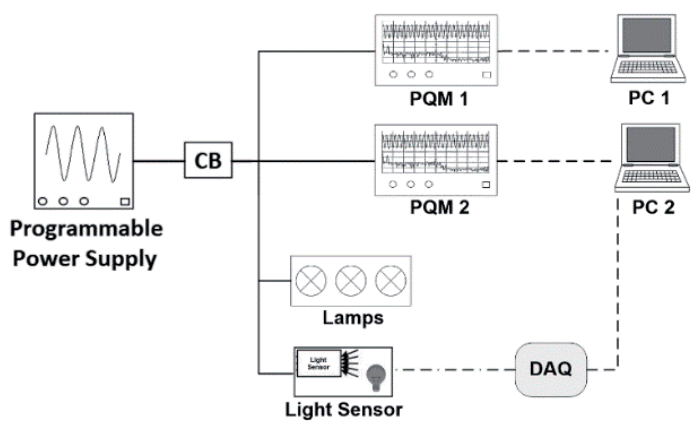

Fig. 13. Schematic diagram of experimental setup to analyze the illuminance variation.

Figures 14 and 15 illustrate, respectively, the illuminance and its frequency spectrum for the three lamps analyzed so far. Table V shows the numeric results. For this case study, the frequencies of illuminance waveforms at three lamps (46.5 Hz for IL and $27.5 \mathrm{~Hz}$ for CFL and LED) are different from the frequency of voltage fluctuation $(13.58 \mathrm{~Hz})$. It is can be explained by the different response of each lamp when there are high interharmonics at the voltage signal.

\section{PROPOSED APPROACH}

The experimental results have revealed that a good way to evaluate the flicker effect is analysing the frequency and magnitude fluctuation of illuminance. If it is known the flicker limit related to the illuminance magnitude for each frequency located at $0-30 \mathrm{~Hz}$ range, a new sensitivity curve can be developed to evaluate the flicker effect. It is well known that flicker effect can be observed in an incandescent lamp for Pst value above 1.0 pu. In this regard, a good strategy to consider all sensibility frequency range of the sensor light, without requiring a group of volunteers, is acquired by analyzing the frequency and magnitude of illuminance in the incandescent lamp while the Pst is equal to $1.0 \mathrm{pu}$ for each frequency located at $0-30 \mathrm{~Hz}$ range. As a result of this strategy, it was obtained a new flicker sensibility curve through the performed sweep frequency response. Even though it was used an incandescent lamp, this curve can be applied for any lamp since the flicker effect was acquired by a direct response of the modulation light.

TABLE V

Numeric Results of Illuminance Variation for IL, CFL and LED lamp at $f=166.5 \mathrm{~Hz}$ and $m=8 \%$

\begin{tabular}{cccc}
\hline \multirow{2}{*}{ Parameter } & \multicolumn{3}{c}{ Lamp Type } \\
\cline { 2 - 4 } & IL & CFL & LED \\
\hline Frequency analyzed $[\mathrm{Hz}]$ & 46.5 & 27.25 & 27.25 \\
\hline Illuminance magnitude [\%] & 0.18 & 0.92 & 1.06 \\
\hline
\end{tabular}
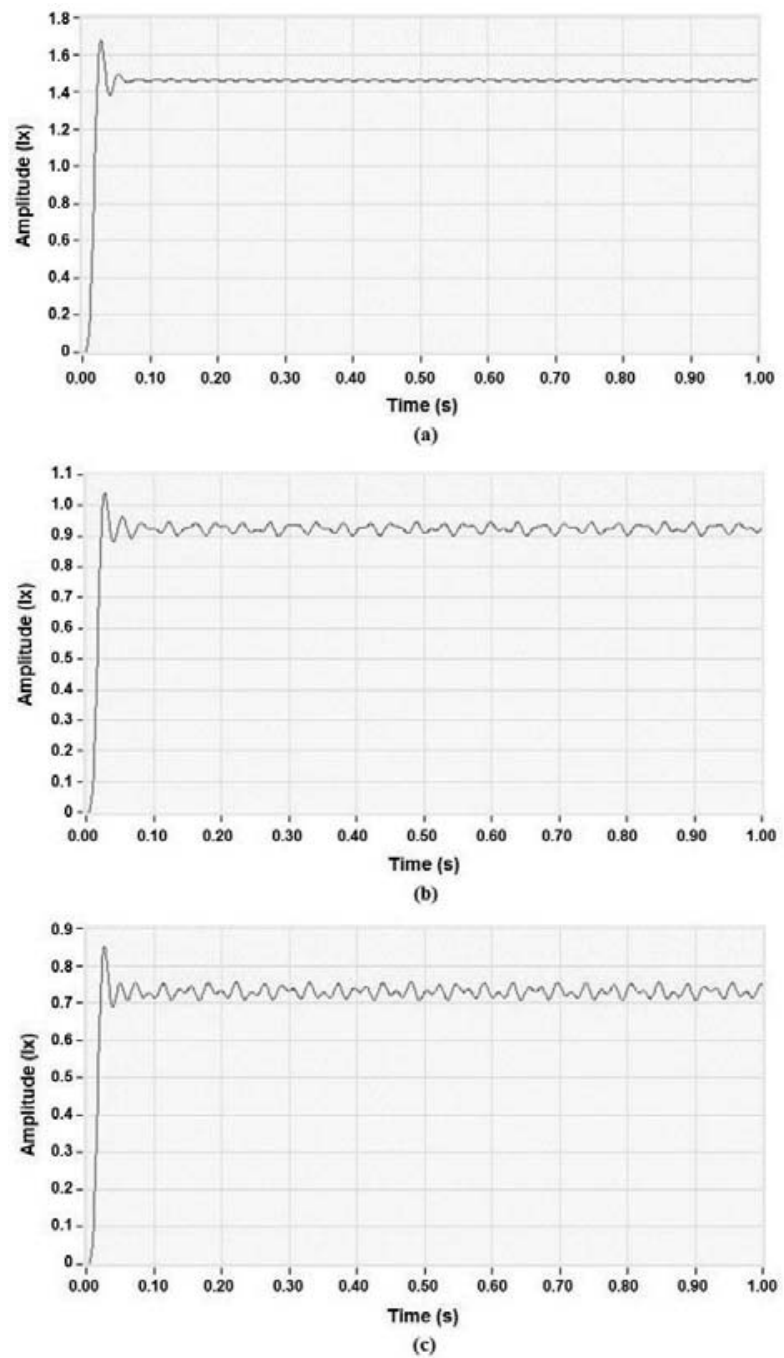

Fig. 14. Illuminance waveform - Case study: $f=166.5 \mathrm{~Hz}, m=8 \%$ : (a) IL lamp; (b) CFL lamp; (c) LED lamp. 


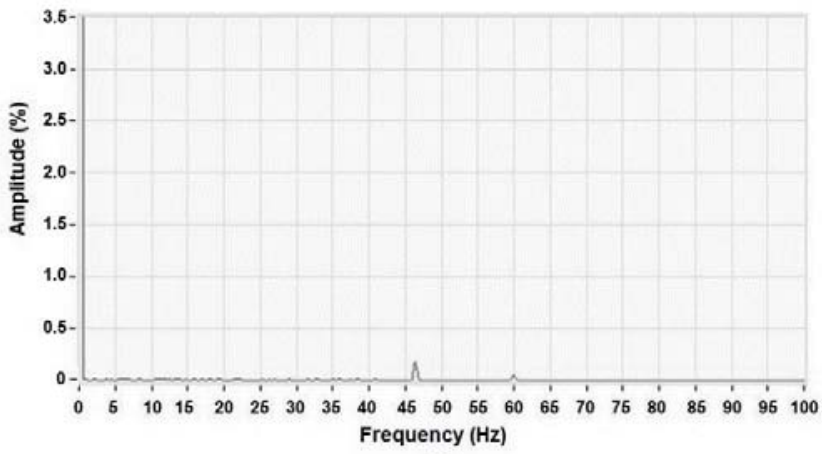

(a)

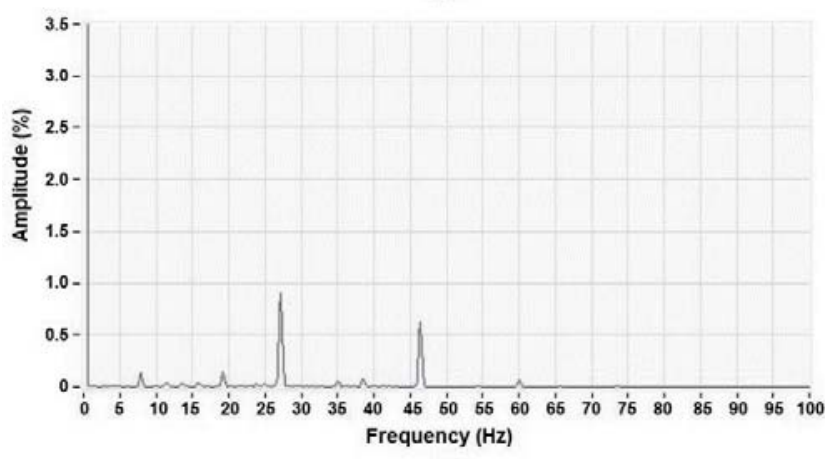

(b)

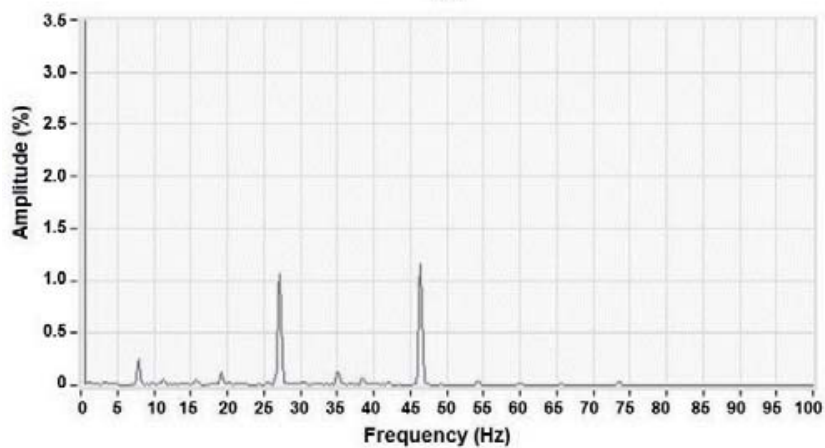

(c)

Fig. 15. Illuminance frequency spectrum - Case study: $f=166.5$ $\mathrm{Hz}, m=8 \%$ : (a) IL lamp; (b) CFL lamp; (c) LED lamp.

Figure 16 illustrates four sensibility curves (solid lines) based on the illuminance variation taking into account 0.5 pu, $1.0 \mathrm{pu}, 2.0 \mathrm{pu}$ and $3.0 \mathrm{pu}$ Pst value.

After measuring, the $0.5 \mathrm{pu}, 2.0 \mathrm{pu}$ and $3.0 \mathrm{pu}$ sensibility curves were calculated as follows:

$$
\operatorname{lux}_{[K] p u}(f)=k \cdot \operatorname{lux} x_{1.0 p u}(f)
$$

where:

$k$ - value in [pu], which indicates the sensibility curve to be calculated.

$\operatorname{lux}_{[K] p u}(f) \quad$ - illuminance magnitude $[\mathrm{mlx}]$ related to the $k$ pu sensibility curve for a frequency $f$ located at $0-30 \mathrm{~Hz}$ range.

$\operatorname{lux}_{1,0 p u}(f) \quad$ - illuminance magnitude $[\mathrm{mlx}]$ related to the $1.0 \mathrm{pu}$ sensibility curve for a frequency $f$ located at $0-30 \mathrm{~Hz}$ range.

The calculated curves using (3) are also presented in Figure 16 (dashed lines). From that, it was possible to verify that illuminance variation is directly proportional to the reference curve. As highlighted by Table VI, the Pearson correlation coefficients indicated a good approximation between the measured and calculated curves. As expected, the point of maximum sensitivity of the flicker lux meter is located around $8.8 \mathrm{~Hz}$.

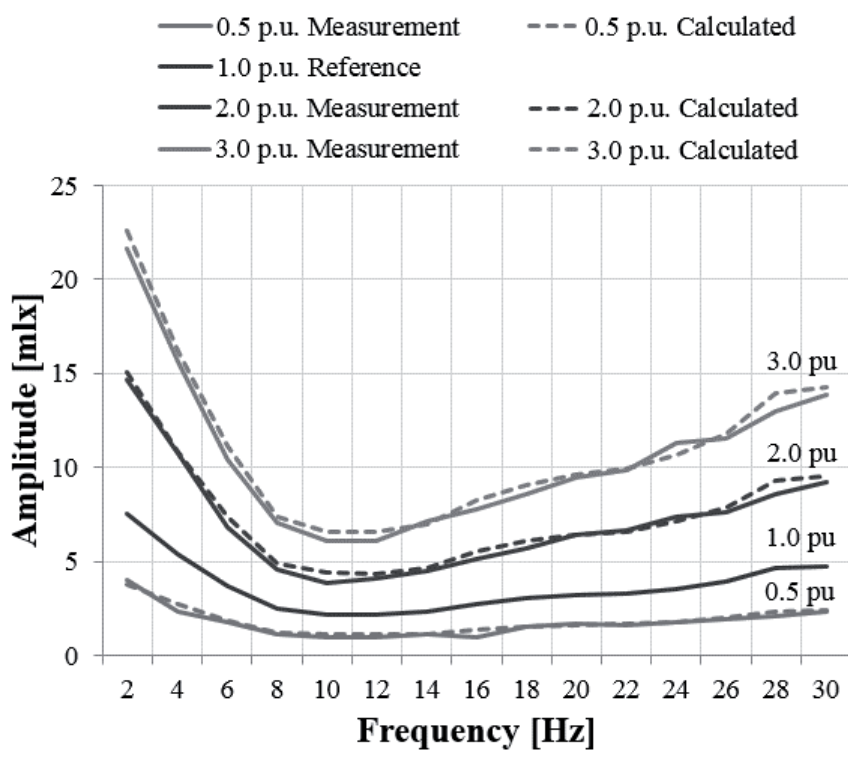

Fig. 16. Flicker sensibility curves based on the illuminance variation - "Flicker Lux Meter".

TABLE VI

Correlation Analysis for the Measured and Calculated Sensibility Curves

\begin{tabular}{cc}
\hline Sensibility curve & Pearson Correlation Coefficient \\
\hline $0.5[\mathrm{pu}]$ & 0.9793 \\
\hline $2.0[\mathrm{pu}]$ & 0.9961 \\
\hline $3.0[\mathrm{pu}]$ & 0.9965
\end{tabular}

The next step was to introduce an index to indicate the flicker severity. This new index was called a $P_{l u x}$. Then, it was developed a polynomial equation, shown in (4), to represent the reference sensibility curve of the flicker lux meter highlighted in Figure 17. For that, it was used the least-square polynomial approximation, which was developed in LabView software.

$$
\operatorname{lux}_{1.0 p u}\left(f_{\text {lux }}\right)=a_{0} \cdot f_{\text {lux }}{ }^{0}+\ldots+a_{i} \cdot f_{\text {lux }}{ }^{i}=\sum_{i=0}^{k} a_{k} \cdot f_{\text {lux }}^{k}
$$

where:

$f_{l u x} \quad-$ illuminance frequency $[\mathrm{Hz}]$.

$a_{0}, a_{1}, \ldots, a_{i} \quad$ - polynomial coefficients (5):

$$
\begin{aligned}
& a_{0}=1.755 \\
& a_{1}=-0.339 \\
& a_{2}=0.028 \\
& a_{3}=-943.7 \cdot 10^{-6} \\
& a_{4}=11.58 \cdot 10^{-6}
\end{aligned}
$$

As the flicker sensibility curves of the flicker lux meter are directly proportional with different $P s t$ values, the new index, $P_{l u x}$, can be calculated by: 


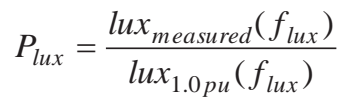

where:

lux $x_{\text {measured }}\left(f_{\text {lux }}\right)$ - illuminance magnitude $[\mathrm{mlx}]$ measured for a specific illuminance frequency, $f_{l u x}$.

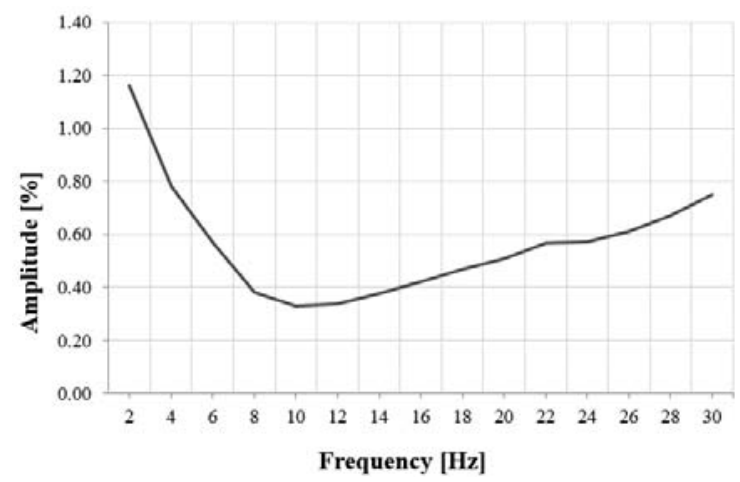

Fig. 17. Final reference sensibility curve (1,0 p.u.) inserted into the flicker lux meter.

Figure 18 presents the approximate curve (dashed line), as well as the reference sensibility curve of flicker lux meter (solid line). It can be seen a good approximation between the both curves.

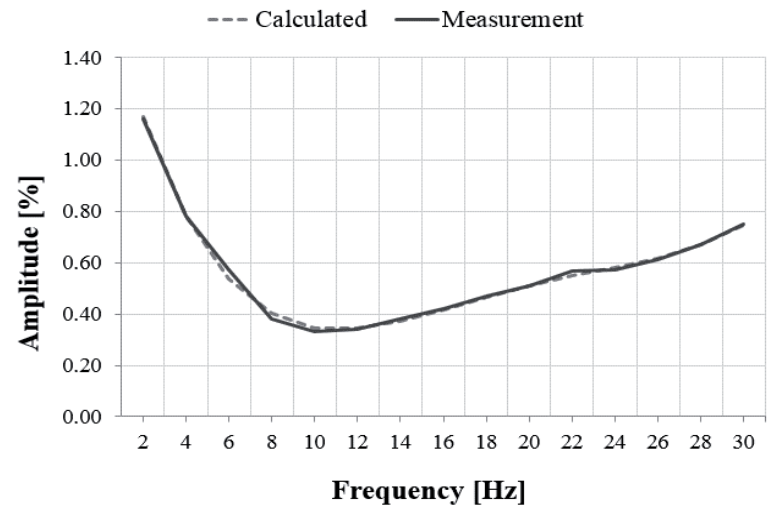

Fig. 18. Approximate curve and reference sensibility curve of flicker lux meter.

To evaluate the flicker lux meter performance, the new flicker severity index, $P_{l u x}$, was calculated and compared to the $P_{s t}$ index taking into account the characteristics of the three case studies analyzed in section II. Tables VII to IX summarize the numeric results for each case study.

From the results, it can be seen that only the flicker lux meter had a good performance for all case studies. The IEC flickermeter failed for the case study 2 .

\section{TABLE VII}

IEC Flickermeter and Flicker Lux Meter Performance for an IL, CFL and LED lamp - Case Study 1: $f=10 \mathrm{~Hz}$, $m=1 \%$

\begin{tabular}{cccc}
\hline \multirow{2}{*}{ Parameter } & \multicolumn{3}{c}{ Lamp Type } \\
\cline { 2 - 4 } & IL & CFL & LED \\
\hline Flicker perception & Yes & Yes & Yes \\
\hline$P_{s t}[\mathrm{pu}]($ IEC Flickermeter $)$ & 2.49 & 2.49 & 2.49 \\
\hline$P_{l u x}[\mathrm{pu}]$ & 1.54 & 1.04 & 1.44 \\
\hline
\end{tabular}

TABLE VIII

IEC Flickermeter and Flicker Lux Meter Performance for IL, CFL and LED lamp - Case Study 2: $f=166.5 \mathrm{~Hz}$, $m=8 \%$

\begin{tabular}{cccc}
\hline \multirow{2}{*}{ Parameter } & \multicolumn{3}{c}{ Lamp Type } \\
\cline { 2 - 4 } & IL & CFL & LED \\
\hline Flicker perception & No & Yes & Yes \\
\hline$P_{s t}[\mathrm{pu}]($ IEC Flickermeter $)$ & 0.53 & 0.79 & 0.54 \\
\hline$P_{l u x}[\mathrm{pu}]$ & 0.03 & 1.42 & 1.65 \\
\hline
\end{tabular}

TABLE IX

IEC Flickermeter and Flicker Lux Meter Performance for IL, CFL and LED lamp - Case Study 3: $f=200 \mathrm{~Hz}$, $m=10 \%$

\begin{tabular}{cccc}
\hline \multirow{2}{*}{ Parameter } & \multicolumn{3}{c}{ Lamp Type } \\
\cline { 2 - 4 } & IL & CFL & LED \\
\hline Flicker perception & No & No & No \\
\hline$P_{s t}[\mathrm{pu}]($ IEC Flickermeter $)$ & 0.44 & 0.46 & 0.47 \\
\hline$P_{\text {lux }}[\mathrm{pu}]$ & 0.002 & 0.37 & 0.77 \\
\hline
\end{tabular}

By applying a relative voltage fluctuation of $1 \%$ at the range $2-30 \mathrm{~Hz}$ in 17 different lamps (IL, CFL and LED type), it can be noted from Figure 19 that great part of CFL and LED lamps tested have a similar response. Therefore, it can be concluded that such lamps would present a similar response of those ones presented in Tables VII, VIII and IX. Moreover, these results highlight that $P_{l u x}$ is a robustness index to be used as reference for further works.

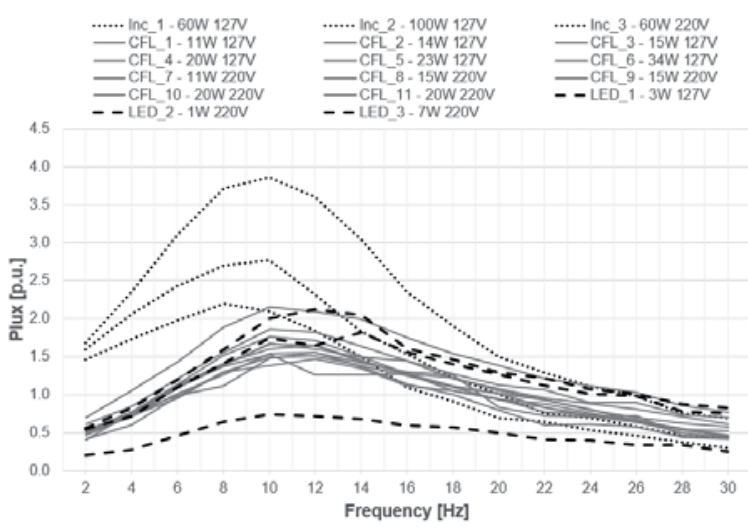

Fig. 19. $P_{l u x}$ characterisitic for different lamps under fluctuation magnitude of $1 \%$.

\section{CONCLUSIONS}

Initially, this paper highlighted the limitations of the current meter for evaluating the flicker effect. It was shown that high interharmonics, above $102 \mathrm{~Hz}$ (60 Hz systems), are neglected by the IEC flickermeter. In this regard, there are situations that Pst index presents a discrepancy with the human observation of flicker. This fact was shown through laboratorial analysis. As a result, this work proposed a new method to evaluate the flicker effect based on the illuminance variation. Then, it was performed experiment tests to analyze the illuminance by using a sensor light. From these tests, it was developed a new flicker sensibility curve. It was observed that the flicker severity index based on the illuminance sensibility curve, called a Plux, had a better response than the Pst index measured by the IEC flickermeter. Compared with major reviewed works, the 
main feature of the proposed method is the introduction of a new short-term flicker severity, which will serve for further works as a reference to extend the analysis to other voltage fluctuations impacts and flicker effect itself by using only the voltage signal as input. Finally, it is worthwhile to point out that the test results are encouraging and the authors believe that the presented proposal may serve as a better way to evaluate the voltage fluctuation effect caused by interharmonic sources, specially those ones produced by VFDs and dc electric arc furnaces, which have significant presence of interharmonics around the harmonics of the ac/dc converters.

\section{ACKNOWLEDGEMENT}

The authors express their gratitude to CAPES for the financial assistance given towards the doctoral degree Graduate course of the Federal University of Uberlandia as well as throughout the research process BEX 17271/12-6.

\section{REFERENCES}

[1] IEC 60050-161, “International Electrotechnical Vocabulary (IEV) - Chapter 161: Electromagnetic compatibility", International Electrotechnical Commission, September/1990.

[2] IEEE Task Force on Harmonics Modeling and Simulation, "Interharmonics: Theory and Modeling", IEEE Transactions on Power Delivery, vol. 22, no. 4, pp. 2335-2348, October/2007.

[3] K. Anuradha, B. P. Muni, A. D. R. Kumar, "Electric Arc Furnace Modeling and Voltage Flicker Mitigation by DSTATCOM", in 2008 IEEE Region 10 and the Third International Conference on Industrial and Information Systems (ICIIS), pp. 1-6, 2008.

[4] L. A. Silva, S. P. Pimentel, J. A. Pomilio, "Mitigação de Efeito Flicker por Meio de Compensação Série do Tipo Indutância Negativa Utilizando Inversor Multinível”, Eletrônica de Potência, vol. 13, no. 3, pp. 147-153, August/2008.

[5] W. Komatsu, C. J. Oliveira Jr., P. S. V. Carvalho, "Direct Water Heater Power Control for Reduced Harmonics and Flicker Content with Optimized HalfCycle Power Control", Eletrônica de Potência, vol. 11, no. 3, pp. 175-180, November/2006.

[6] IEC 61000-4-15 Ed.2, "Electromagnetic Compatibility (EMC) - Part 4-15: Testing and measurement techniques - Section 15: Flickermeter Functional and design specifications", International Electrotechnical Commission, August/2010.

[7] Working Group C4.108, "Review of Flickermeter Objectives for LV, MV, and HV Systems", CIGRE Technical Brochure 449, February/2001.

[8] W. Xu, "Deficiency of the Flicker Mater for Measuring Interharmonic-Caused Voltage Flickers", in 2005 IEEE Power Engineering Society General Meeting, vol. 3, pp. 2326-2329, 2005.

[9] T. Tayjasanant, W. Wang, C. Li, W. Xu, "Interharmonic-Flicker Curves", IEEE Transactions on Power Delivery, vol. 20, no. 2, pp. 1017-1024, April/2005.
[10] T. Kim, M. Rylander, E. J. Powers, W. M. Grady, A. Arapostathis, "Detection of Flicker Caused by Interharmonics", IEEE Transaction on Instrumentation and Measurement, vol. 58, no. 1, pp. 152-160, January/2009.

[11] J. Yong, T. Tayjasanant, W. Xu, C. Sun, "Characterizing Voltage Fluctuations Caused by a Pair of Interharmonics" IEEE Transactions on Power Delivery, vol. 23, no. 1, pp. 319-327, January/2008.

[12] K. Zhao, P. Ciufo, S. Perera, "Rectifier Capacitor Filter Stress Analysis When Subject to Regular Voltage Fluctuations", IEEE Transactions on Power Instruments, vol. 28, no. 7, pp. 3627-3635, July/2013.

[13] T. Keppler, N. Watson, J. Arrillaga, "Computation of the short-term flicker severity index", IEEE Transactions on Power Delivery, vol. 15, no. 4, pp. 1110-1115, October/2000.

[14] H. Shyh-Jier, L. Chen-Wen, "Enhancement of digital equivalent voltage flicker measurement via continuous wavelet transform", IEEE Transactions on Power Delivery, vol. 19, no. 2, pp. 663-670, April/2004.

[15] M. Szlosek, B. Swiqtek, Z. Hanzelka, A. Bien, "Application of neural networks to voltage fluctuations measurement-a proposal for a new flickermeter", in 11th International Conference on Harmonics and Quality of Power, pp. 403-407, 2004.

[16] A. Zargari, P. Moallem, A. Kiyoumarsi, "Studying and Improvement of Operation of IEC Flickermeter", in 18th Electrical Engineering (ICEE), pp. 925-931, 2010.

[17] C. Rong, J. F. G. Cobben, J. M. A. Myrzik, J. H. Blom, W. L. Kling, "Flickermeter Used for Different Types of Lamps", in 2007 Electrical Power Quality and Utilisation (EPQU'11), pp. 1-6, 2007.

[18] A. E. Emanuel, L. Peretto, "A Simple Lamp-EyeBrain Model for Flicker Observations", IEEE Transactions on Power Delivery, vol. 19, no. 3, pp. 1308-1313, July/2004.

[19] L. Peretto, E. Pivello, R. Tinarelli, A. E. Emanuel, "Theoretical Analysis of the Physiologic Mechanism of Luminous Variation in Eye-Brain System", IEEE Transactions on Instrumentations and Measurement, vol. 56, no. 1, pp. 164-170, February/2007.

[20] L. Peretto, C. E. Riva, L. Rovati, G. Salvatori, R. Tinarelli, "Analysis of the Effects of Flicker on the Blood-Flow Variation in the Human Eye", IEEE Transactions on Instrumentation and Measurement, vol. 58, no. 9, pp. 2916-2922, September/2009.

[21] M. G. Masi, L. Peretto, R. Tinarelli, "Flicker Effect Analysis in Human Subjects: New Noninvasive Method for Next-Generation Flickermeter", IEEE Transactions on Instrumentation and Measurement, vol. 60, no. 9, pp. 3018-3025, September/2011.

[22] J. R Macedo Jr., D. S. L. Simonetti, "Análise de desempenho do flickermeter na presença de componentes inter-harmônicas". Sba Controle \& Automação, vol. 23, no. 4, pp. 508-519, Agosto/2012.

[23] G. P. Colnago, J. R. Macedo Jr., J. L. F. Vieira, "Development and implementation of a flickermeter 
with luminous flux variation measurement". Eletrônica de Potência, vol. 18, no. 4, pp. 1235-1244, November/2013.

[24] L. W. White, S. Bhattacharya, "A Discrete MatlabSimulink Flickermeter Model for Power Quality Studies", IEEE Transactions on Instrumentation and Measurement, vol. 59, no. 3, pp. 527-533, $\mathrm{March} / 2010$.

[25] IEC 61000-2-1: 1990, Ed. 1, "Electromagnetic Compatibility (EMC) - Part 2: Environment - Section 1: Description of the Environment - Electromagnetic environment for low-frequency conducted disturbances and signaling in public power supply systems", International Electrotechnical Commission, May/1990.

[26] IEEE Std. 1453-2004, “IEEE Power Engineering Society - IEEE Recommended Practice for Measurement and Limits of Voltage Fluctuations and Associated Light Flicker on AC Power Systems", March/2005.

[27] A. Testa, M. F. Akran, R. Burch, G. Carpinelli, G. Chang, V. Dinavahi, C. Hatziadoniu, W. M. Grady, E. Gunther, M. Halpin, P. Lehn, Y. Liu, R. Langella, M. Lowenstein, A. Medina, T. Ortmeyer, S. Ranade, P. Ribeiro, N. Watson, J. Wikston, W. Xu, "Interharmonics: Theory and Modeling - IEEE Task Force on Harmonics Modeling and Simulation", IEEE Transactions on Power Delivery, vol.22, no.4, pp. 2335-2348, October/2007.

[28] C. May, E. R. Collins, "An investigation of the response of incandescent lamps and compact fluorescent lamps to voltage fluctuations", in 14th International Conference on Harmonics and Quality of Power (ICHQP), pp. 1-8, 2010.

[29] Y. N. Chang, C. C. Hung, "Electronic Ballast with Constant Instantaneous Power Output for Fluorescent
Lamps without Light Fluctuation", in 2007 Power Conversion Conference (PCC'07), pp. 721-726, 2007.

[30] S. Uddin, H. Shareef, A. Mohamed, M. A. Hannan, "Analysis of Voltage Sag Sensitivity of LED Lamps", in 2012 IEEE International Conference on Power and Energy (PECon), pp. 667-670, 2012.

[31] C. K. Lee, S. Li, S. Y. Hui, "A Design Methodology for Smart LED Lighting Systems Powered By Weakly Regulated Renewable Power Grids", IEEE Transactions on Smart Grids, vol. 2, no. 3, pp. 548554, September/2011.

\section{BIOGRAPHIES}

Arnaldo Jose Pereira Rosentino Junior received the B.Sc. and the M.Sc. degree in electrical engineering from the Federal University of Uberlandia - MG, Brazil, in 2008 and 2010 respectively. Currently, he is $\mathrm{PhD}$ candidate in electrical engineering at Federal University of Uberlandia, Brazil.

Jose Rubens Macedo Junior received the B.S. degree from Federal University of Uberlandia, Brazil, and the Ph.D. degree from Federal University of Espírito Santo, Brazil. Currently, he is a Professor of electrical engineering with the Federal University of Uberlandia.

Antonio Carlos Delaiba received his B. Sc. degree (electrical engineering) from Educational Foundation of Barretos, Brazil, in 1979. He obtained his M.Sc. and Ph.D. degrees in electrical engineering from the Polytechnic School of the University of Sao Paulo, Sao Paulo, Brazil, in 1987 and 1997 respectively. Currently he is professor at electrical engineering department of Federal University of Uberlandia. 